\title{
Analisis Arus Gangguan Hubung Singkat Sistem Tenaga Listrik Dengan Aplikasi Matlab
}

\author{
Yulisman \\ Prodi Teknik Elektro Fakultas Teknik UMSB \\ email: fte.umsb12@gmail.com
}

\begin{abstract}
Electricity generated from the power plant which is then transmitted through the transmission to the distribution network and the user to be used in everyday life. This distribution process is not free from disruptions arising from material factor/conductor types and distance factor.

Short circuit current which is happened in elektrical power system can caused disconnection in distributing electrical power to costumers. One of the efforts to overcome the interruptions is to do an analysis in short circuit an ealy stage with the result that we could find a pricise protection system on our electrical power system.

Short circuit can be analyzed using simulation methods and calculations manually to determine how much the short-circuit current that occurs at different bus each in turn. The method used study with a single line diagram, perform manual short circuit calculations and using Matlab, and making comparisons and conclusions.
\end{abstract}

Key word : analysis, current, Matlab, short circuit.

Abstrak: Listrik dihasilkan dari pembangkit listrik yang kemudian ditransmisikan melalui jaringan transmisi sampai pada distribusi dan pengguna untuk dimanfaatkan dalam kehidupan sehari-hari. Proses penyaluran ini tidak lepas dari gangguan yang timbul akibat dari faktor bahan/jenis penghantar dan faktor jarak.

Gangguan hubung singkat yang terjadi pada sistem tenaga listrik dapat mengakibatkan terputusnya penyaluran tenaga listrik kepada konsumen. Salah satu upaya untuk mengatasi gangguan hubung singkat tersebut dilakukan analisis hubung singkat sebagai tahap awal untuk menanggulanginya sehingga sistem proteksi yang tepat pada sistem tenaga listrik dapat ditentukan.

Gangguan hubung singkat dapat dianalisa dengan menggunakan metode simulasi dan perhitungan manual dengan tujuan untuk mengetahui seberapa besar arus hubung singkat yang terjadi di tiap bus yang berbeda secara bergantian. Metode yang digunakan dalam penulisan ini adalah dimulai dari diagram satu garis, melakukan perhitungan arus hubung singkat manual dan menggunakan Matlab, dan membuat perbandingan dan kesimpulan.

Kata kunci : analisa, arus, Matlab, gangguan hubung singkat.

\section{PENDAHULUAN}

Tenaga listrik disalurkan ke konsumen melalui sistem tenaga listrik. Sistem tenaga listrik terdiri dari beberapa sub-sistem, yaitu pembangkitan, transmisi, dan distribusi. Dalam pengoperasian sistem tenaga listrik sering terjadi gangguan-gangguan yang dapat mengakibatkan terganggunya penyaluran tenaga listrik ke konsumen. Gangguan adalah penghalang dari suatu sistem yang sedang beroperasi atau suatu keadaan dari sistem penyaluran tenaga listrik yang menyimpang dari kondisi normal. Berdasarkan ANSI/IEEE Std. 100-1992, gangguan didefinisikan sebagai suatu kondisi fisis yang disebabkan kegagalan suatu perangkat, komponen, atau suatu elemen untuk bekerja sesuai dengan fungsinya. Gangguan hampir selalu ditimbulkan oleh hubung singkat antar fasa atau hubung singkat fasa ke tanah. Suatu gangguan hampir selalu berupa hubung langsung atau melalui impedansi. Istilah gangguan identik dengan hubung singkat, yang merupakan 
suatu hubungan abnormal pada impedansi yang relatif rendah terjadi secara kebetulan atau disengaja antara dua titik yang mempunyai potensial yang berbeda. Istilah gangguan atau gangguan hubung singkat digunakan untuk menjelaskan suatu hubungan singkat.

Untuk mengatasi gangguan tersebut, perlu dilakukan analisis hubung singkat sehingga sistem pengaman (proteksi) dari sistem tenaga listrik tersebut dapat ditentukan dengan tepat. Analisis hubung singkat adalah analisis yang mempelajari kontribusi arus gangguan hubung singkat yang mungkin mengalir pada setiap cabang di dalam sistem (di jaringan distribusi, transmisi, trafo tenaga atau dari pembangkit) sewaktu gangguan hubung singkat yang mungkin terjadi di dalam sistem tenaga listrik.

\section{METODE PENELITIAN}

Gangguan-gangguan pada sistem tenaga listrik dapat dibagi dalam dua golongan, yaitu hubung singkat (gangguan shunt) dan gangguan hubung terbuka (gangguan seri). Macam gangguan hubung singkat sendiri dapat dibedakan atas, yaitu gangguan hubung singkat tiga fasa (K-K-K), gangguan hubung singkat dua fasa (K-K), gangguan hubung singkat dua fasa ke tanah (K-K-T), dan gangguan hubung singkat satu fasa ke tanah (K-T). Berdasarkan lama waktu gangguan maka macam gangguan dapat dibagi lagi menjadi dua, yaitu gangguan yang bersifat sementara dan gangguan yang bersifat menetap.

Beberapa metoda yang dapat digunakan untuk studi hubung singkat antara lain, metoda matrik impedansi bus, metoda matrik admitansi bus (kedua metoda ini menggunakan teori komponen simetris) dan metoda koordinat fasa. Dalam penulisan ini pembahasannya menggunakan metoda matrik impedansi bus.

Untuk gangguan tiga fasa seimbang cenderung disederhanakan dengan pendekatan per fasa. Diagram satu garis sederhana untuk menyelesaikan masalah gangguan tiga fasa seimbang dengan metode komponen simetris adalah untuk memecahkan penyelesaian rangkaian tidak seimbang ke dalam sebuah rangkaian yang seimbang.

\section{Komponen Simetris}

Prinsip dasar komponen simetris adalah, suatu kumpulan tiga hubungan vektor yang tidak seimbang, yang dapat diuraikan menjadi tiga set vektor yang seimbang. Ketiga set vektor yang seimbang itu biasa disebut dengan komponen urutan positif, komponen urutan negatif, dan komponen urutan nol.

Penggunaan komponen simetris pada sistem tiga fasa memerlukan suatu satuan fasor atau operator yang akan memutar rotasi fasor dengan fasor lainnya yang berbeda fasa $120^{\circ}$. Bila dipakai fasor operator satuan adalah a, maka :

$a=-0,5+j 0,866$ dan $a^{2}=-0,5-j 0,866$

Fasor tiga fasa tidak seimbang dari sistem tiga fasa dapat dipecahkan ke dalam fasor tiga fasa seimbang sebagai berikut :

- Komponen urutan positif, terdiri dari seperangkat komponen tiga fasa seimbang dan mempunyai urutan fasa yang sama dengan fasor-fasor aslinya.

- Komponen urutan negatif, terdiri dari seperangkat komponen tiga fasa seimbang dan mempunyai urutan fasa yang berlawanan dengan fasor-fasor aslinya.

- Komponen urutan nol, terdiri dari komponen satu fasa yang semuanya sama besar dan mempunyai sudut fasa yang sama. Komponen simetris arus tak seimbang :

$\mathrm{I}_{\mathrm{a} 0}=1 / 3\left(\mathrm{I}_{\mathrm{a}}+\mathrm{I}_{\mathrm{b}}+\mathrm{I}_{\mathrm{c}}\right)$

$I_{a 1}=1 / 3\left(I_{a}+a I_{b}+a^{2} I_{c}\right)$

$I_{a 2}=1 / 3\left(I_{a}+a^{2} I_{b}+a I_{c}\right)$

Komponen simetris tegangan tak seimbang adalah :

$\mathrm{V}_{\mathrm{a} 0}=1 / 3\left(\mathrm{~V}_{\mathrm{a}}+\mathrm{V}_{\mathrm{b}}+\mathrm{V}_{\mathrm{c}}\right)$

$\mathrm{V}_{\mathrm{a} 1}=1 / 3\left(\mathrm{~V}_{\mathrm{a}}+\mathrm{a} \mathrm{V}_{\mathrm{b}}+\mathrm{a}^{2} \mathrm{~V}_{\mathrm{c}}\right)$

$\mathrm{V}_{\mathrm{a} 2}=1 / 3\left(\mathrm{~V}_{\mathrm{a}}+\mathrm{a}^{2} \mathrm{~V}_{\mathrm{b}}+\mathrm{aV}_{\mathrm{c}}\right)$

Gangguan yang sering terjadi pada sistem tenaga listrik merupakan gangguan tidak simetris sehingga memerlukan metode komponen simetris untuk menganalisa tegangan dan arus pada saat terjadinya gangguan. Gangguan yang terjadi dapat dianalisa dengan menghubung-singkatkan semua sumber tegangan yang ada pada sistem dan mengganti titik (node) gangguan dengan sebuah sumber tegangan yang besarnya sama dengan tegangan sesaat sebelum terjadinya gangguan di titik gangguan tersebut. Dengan menggunakan 
metode ini sistem tiga fasa tidak seimbang dapat direpresentasikan dengan menggunakan teori komponen simetris yaitu berdasarkan komponen urutan positif, komponen urutan negatif dan komponen urutan nol.

\section{Gangguan Hubung Singkat 1 Fasa Tanah}

Gangguan satu fasa ke tanah akan menyebabkan kenaikan arus pada fasa terganggu dan tegangan menjadi nol, sedangkan arus pada fasa lain menjadi nol yang diikuti dengan kenaikan tegangan pada fasa yang lain. Komponen urutan arus gangguan adalah :

$$
I_{a 0}=I_{a 1}=I_{a 2}=\frac{V_{a}}{Z_{1}+Z_{2}+Z_{0}+3 Z_{f}}
$$

Arus gangguan adalah :

$$
\begin{aligned}
& {\left[\begin{array}{c}
I_{a} \\
I_{b} \\
I_{c}
\end{array}\right]=\left[\begin{array}{lll}
1 & 1 & 1 \\
1 & a^{2} & a \\
1 & a & a^{2}
\end{array}\right]\left[\begin{array}{c}
I_{a 0} \\
I_{a 1} \\
I_{a 2}
\end{array}\right]} \\
& I_{f}=3 I_{a 0}=\frac{3 V_{a}}{Z_{1}+Z_{2}+Z_{0}+3 Z_{f}}
\end{aligned}
$$

\section{Gangguan Hubung Singkat 2 Fasa Tanah}

Gangguan dua fasa ke tanah terjadi ketika dua buah fasa dari sistem tenaga listrik terhubung singkat dengan tanah. Komponen urutan positif dari arus gangguan adalah :

$I_{a 1}=-\frac{V_{a}}{Z_{1}+\frac{Z_{2}\left(Z_{0}+3 Z_{f}\right)}{Z_{2}+Z_{0}+3 Z_{f}}}$ arus urutan negatif adalah :

$$
I_{a 2}=-\frac{V_{a}-Z_{1} I_{a 1}}{Z_{2}}
$$

Komponen arus urutan nol adalah :

$I_{a 0}=-\frac{V_{a}-Z_{1} I_{a 1}}{Z_{0}+3 Z_{f}}$
Arus fasa

$$
\left[\begin{array}{c}
I_{a} \\
I_{b} \\
I_{c}
\end{array}\right]=\left[\begin{array}{ccc}
1 & 1 & 1 \\
1 & a^{2} & a \\
1 & a & a^{2}
\end{array}\right]\left[\begin{array}{c}
I_{a 0} \\
I_{a 1} \\
I_{a 2}
\end{array}\right]
$$

Arus gangguan :

$$
I_{f}=I_{n}=I_{b}+I_{c}=3 I_{a 0}
$$

\section{Gangguan Hubung Singkat 2 Fasa}

Gangguan hubung singkat fasa ke fasa, arus saluran tidak mengandung komponen urutan nol, dikarena-kan tidak ada gangguan yang terhubung ke tanah. Komponen $I_{a 0}=0$ arus urutan nol adalah :

Komponen urutan positif dan negatif arus gangguan adalah :

$$
I_{a 1}=-I_{a 2}=\frac{V_{a}}{Z_{1}+Z_{2}+3 Z_{f}}
$$

Arus fasa adalah :

$$
\left[\begin{array}{c}
I_{a} \\
I_{b} \\
I_{c}
\end{array}\right]=\left[\begin{array}{ccc}
1 & 1 & 1 \\
1 & a^{2} & a \\
1 & a & a^{2}
\end{array}\right]\left[\begin{array}{c}
I_{a 0} \\
I_{a 1} \\
I_{a 2}
\end{array}\right]
$$

Arus gangguan :

$$
I_{f}=I_{b 1}+I_{b 2}=\frac{\sqrt{3} V_{a}}{Z_{1}+Z_{2}+3 Z_{f}}
$$

\section{Gangguan Hubung Singkat 3 Fasa}

Gangguan hubung singkat 3 fasa termasuk dalam klasifikasi gangguan simetris, sehingga pada sistem seperti ini dapat dianalisa hanya dengan mengguna-kan komponen urutan positif saja.

Suatu gangguan menghadirkan sebuah perubahan struktur jaringan ekivalen yang disebabkan oleh penambahan impedansi pada tempat gangguan, jaringan yang terganggu diatasi dengan metoda Thevenin yang menyatakan perubahan tegangan pada jaringan disebabkan oleh penambahan cabang (impedansi gangguan). Persamaan arus gangguannya adalah :

$$
I_{f}=\frac{V_{a}}{Z_{1}+Z_{f}}
$$

\section{Objek Penulisan}

Objek dari penulisan ini adalah suatu sistem tenaga listrik yang mempunyai 3 bus seperti diperlihatkan pada gambar-1 berikut, dimana netral setiap generator diketanahkan melalui reaktor pembatas arus senilai 0,25 pu pada dasar 100 MVA. Data sistem diekspresikan dalam pu mengikuti dasar 100 MVA, sebagai berikut :

$\mathrm{G}_{1}: 100$ MVA, $20 \mathrm{kV}, \mathrm{X}_{1}=0,15 \quad \mathrm{X}_{2}=0,15$ $\mathrm{X}_{0}=0,05$ 
$\mathrm{G}_{2}: 100$ MVA, $20 \mathrm{kV}, \mathrm{X}_{1}=0,15 \quad \mathrm{X}_{2}=0,15$

$\mathrm{X}_{0}=0,05$

$\mathrm{T}_{1}: 100 \mathrm{MVA}, 20 / 220 \mathrm{kV}, \mathrm{X}_{1}=0,10 \quad \mathrm{X}_{2}=0,10$

$\mathrm{X}_{0}=0,10$

$\mathrm{T}_{2}$ : $100 \mathrm{MVA}, 20 / 220 \mathrm{kV}, \mathrm{X}_{1}=0,10 \quad \mathrm{X}_{2}=0,10$ $\mathrm{X}_{0}=0,10$

$\mathrm{L}_{12}: 100 \quad$ MVA, $220 \mathrm{kV}, \quad \mathrm{X}_{1}=0,125$ $\mathrm{X}_{2}=0,125 \quad \mathrm{X}_{0}=0,30$

$\mathrm{L}_{13}$ : 100 MVA, $220 \mathrm{kV}, \mathrm{X}_{1}=0,15 \quad \mathrm{X}_{2}=0,15$ $\mathrm{X}_{0}=0,35$

$\mathrm{L}_{23}$ : $100 \mathrm{MVA}, 220 \mathrm{kV}, \mathrm{X}_{1}=0,25 \quad \mathrm{X}_{2}=0,25$ $\mathrm{X}_{0}=0,7125$

Generator beroperasi tanpa beban pada rating tegangan dan rating frekwensi dengan tegangan emf dalam fasa.

Dalam hal ini akan ditentukan arus gangguan untuk:

a. gangguan tiga fasa seimbang pada bus 3 melalui impedansi gangguan $\mathrm{Z}_{\mathrm{f}}=\mathrm{j} 0,10 \mathrm{pu}$.

b. gangguan satu fasa ke tanah pada bus 3 melalui impedansi gangguan $\mathrm{Z}_{\mathrm{f}}=\mathrm{j} 0,10 \mathrm{pu}$.

c. gangguan fasa ke fasa pada bus 3 melalui impedansi gangguan $\mathrm{Z}_{\mathrm{f}}=\mathrm{j} 0,10 \mathrm{pu}$.

d. gangguan dua fasa ke tanah pada bus 3 melalui impedansi gangguan $\mathrm{Z}_{\mathrm{f}}=\mathrm{j} 0,10 \mathrm{pu}$.

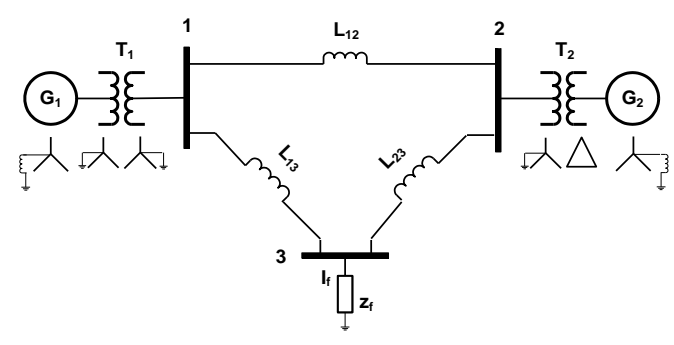

Gambar-1. Diagram satu garis

Prosedur penyelesaiannya sebagai berikut :

Menggambarkan jaringan impedansi urutan positif dari diagram satu garis.

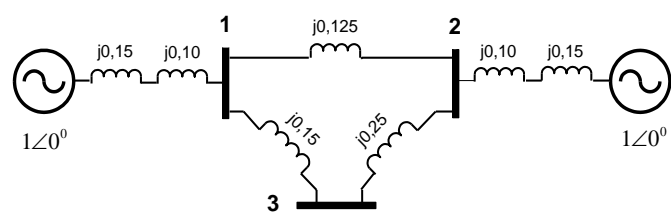

Gambar-2. Diagram impedansi urutan positif

Mencari impedansi Thevenin yang dipandang dari bus gangguan (bus 3) dengan mengubah bentuk segitiga oleh bus $123 \mathrm{ke}$ ekivalen bintang, seperti gambar berikut.

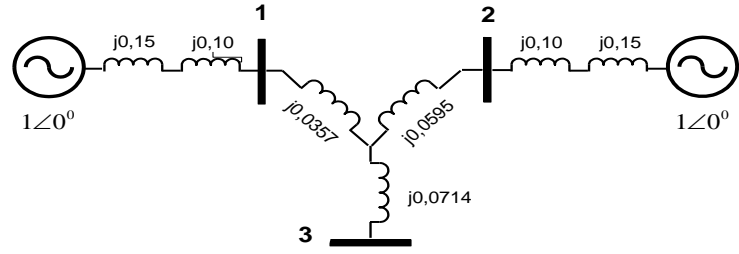

Gambar-3. Diagram ekivalen impedansi urutan positif

Mengkombinasikan cabang paralel, impedansi Thevenin urutan positifnya.

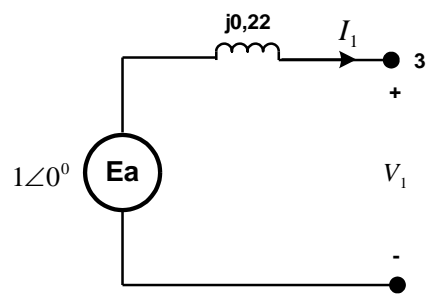

Gambar-4. Jaringan urutan positif

Menentukan impedansi urutan negatif setiap elemen yang mana nilainya sama dengan impedansi urutan positifnya.

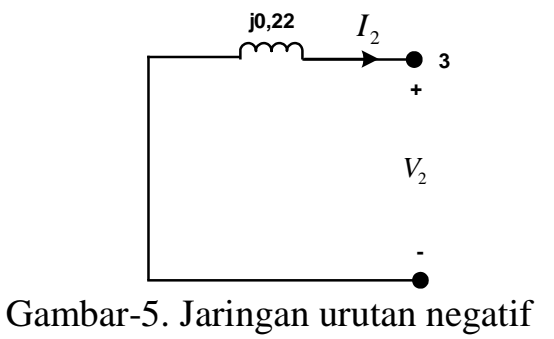

Membangun jaringan urutan nol menurut hubungan belitan transformator.

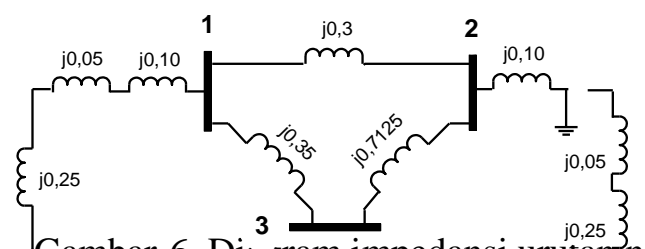

Gambar-6. Diagram impedansi urutan'nol Menentukan impedansi Thevenin "yang dipandang dari bus gangguan (bus 3), dengan mengubah bentuk segitiga bus 123 menjadi ekive 11 bintang. 2

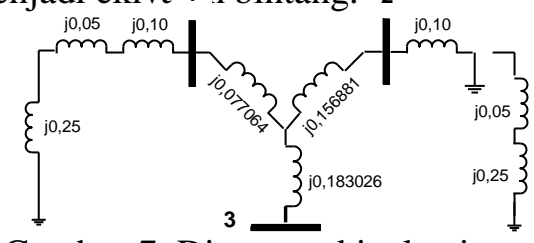

Gambar-7. Diagram ekivalen impedansi urutan nol 
Mengkombinasikan cabang paralel, impedansi Thevenin urutan nolnya.

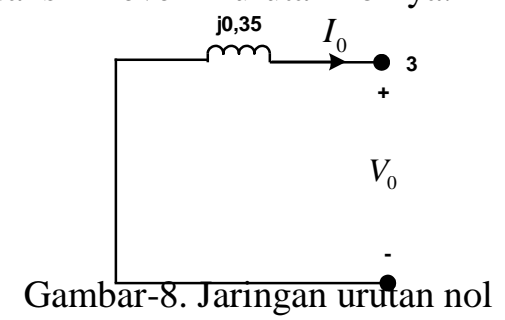

Menentukan arus gangguan untuk :

a. Gangguan tiga fasa seimbang pada bus 3 , dengan asumsi tegangan emf yang dibangkitkan tanpa beban sama dengan 1,0 pu, maka arus gangguan :

$$
\begin{aligned}
I_{f}= & \frac{V_{a}}{Z_{1}+Z_{f}}=\frac{1,0}{j 0,22+j 0,10}=-j 3,125 p u \\
& =3,125 \angle-90^{\circ} \mathrm{pu}
\end{aligned}
$$

b. Gangguan satu fasa ke tanah pada bus 3 , komponen urutan arus gangguan :

$$
\begin{aligned}
I_{a 0} & =I_{a 1}=I_{a 2}=\frac{V_{a}}{Z_{1}+Z_{2}+Z_{0}+3 Z_{f}} \\
& =\frac{1,0}{j 0,22+j 0,22+j 0,35+3(j 0,1)} \\
& =-j 0,9174 p u
\end{aligned}
$$

Arus pada fasa :

$$
\left[\begin{array}{l}
I_{a} \\
I_{b} \\
I_{c}
\end{array}\right]=\left[\begin{array}{ccc}
1 & 1 & 1 \\
1 & a^{2} & a \\
1 & a & a^{2}
\end{array}\right]\left[\begin{array}{l}
-j 0,9174 \\
-j 0,9174 \\
-j 0,9174
\end{array}\right]
$$

Arus gangguan : $0\left[\begin{array}{c}-j 2,7523 \\ 0\end{array}\right] p u$

$$
I_{f}=I_{a}=3 I_{a 0}=-j 2,7523=2,7523 \angle-90^{\circ} \mathrm{pu}
$$

c. Gangguan fasa ke fasa pada bus 3,

Komponen arus urutan $I_{a 0}=0$ nol :

Komponen urutan positif dan urutan negatif dari arus gangguan :

$$
\begin{aligned}
I_{a 1} & =-I_{a 2}=\frac{V_{a}}{Z_{1}+Z_{2}+3 Z_{f}}=\frac{1,0}{j 0,22+j 0,22+3(j 0,1)} \\
& =-j 1,8519 \mathrm{pu}
\end{aligned}
$$

Arus pada fasa :

$$
\left[\begin{array}{l}
I_{a} \\
I_{b} \\
I_{c}
\end{array}\right]=\left[\begin{array}{lll}
1 & 1 & 1 \\
1 & a^{2} & a \\
1 & a & a^{2}
\end{array}\right]\left[\begin{array}{c}
0 \\
-j 1,8519 \\
j 1,8519
\end{array}\right]=\left[\begin{array}{c}
0 \\
-3,2075 \\
3,2075
\end{array}\right.
$$

d. Gangguan dua fasa ke tanah pada bus 3, Komponen urutan positif dari arus gangguan:

$$
\begin{aligned}
I_{a 1} & =-\frac{V_{a}}{Z_{1}+\frac{Z_{2}\left(Z_{0}+3 Z_{f}\right)}{Z_{2}+Z_{0}+3 Z_{f}}} \\
& =-\frac{1,0}{j 0,22+\frac{j 0,22(j 0,35+j 0,3)}{j 0,22+j 0,35+3(j 0,1)}} \\
& =-j 2,6017 p u
\end{aligned}
$$

Komponen urutan negatif dari arus gangguan:

$$
\begin{aligned}
I_{a 2} & =-\frac{V_{a}-Z_{1} I_{a 1}}{Z_{1}}=\frac{1,0-(j 0,22)(-j 2,6017)}{j 0,22} \\
& =j 1,9438 p u
\end{aligned}
$$

Komponen urutan nol

dari arus gangguan :

$$
\begin{aligned}
I_{a 0} & =-\frac{V_{a}-Z_{1} I_{a 1}}{Z_{0}+3 Z_{f}}=-\frac{1,0-(j 0,22)(-j 2,6017)}{j 0,35+3(j 0,10)} \\
& =j 0,6579 p u
\end{aligned}
$$

Arus pada fasa :

$$
\begin{aligned}
{\left[\begin{array}{c}
I_{a} \\
I_{b} \\
I_{c}
\end{array}\right]=} & {\left[\begin{array}{ccc}
1 & 1 & 1 \\
1 & a^{2} & a \\
1 & a & a^{2}
\end{array}\right]\left[\begin{array}{c}
j \\
-j \\
-j
\end{array}\right.} \\
& =\left[\begin{array}{c}
0 \\
4,058 \angle 165,93^{\circ} \\
4,058 \angle 14,07^{\circ}
\end{array}\right]
\end{aligned}
$$

Arus gangguan :

$$
\begin{aligned}
I_{f} & =I_{b}+I_{c}=3 I_{a 0}=j 1,9732 \\
& =1,9732 \angle 90^{0} \mathrm{pu}
\end{aligned}
$$

Penyusunan bahasa pemrograman Matlab guna menganalisis arus gangguan hubung \$ingkat untuk sistem tenaga listrik di atas : 
$\%$

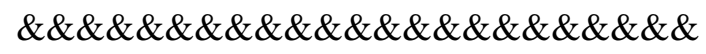

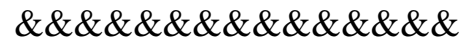

$\% \& \&$ Perhitungan Arus Gangguan pada

Sistem Tenaga Listrik \&

$\%$

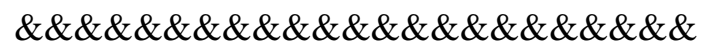

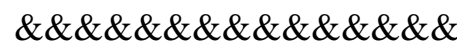

$\%$ Matriks transformasi komponen simetris :

$\mathrm{a}=-0.5+\mathrm{j}^{*} 0.866$;

$\mathrm{A}=\left[111 ; 1 \mathrm{a}^{\wedge} 2 \mathrm{a} ; 1 \mathrm{a} \mathrm{a}^{\wedge} 2\right]$;

$\%$ Data sistem :

V3 a $0=1$

$\mathrm{Zf}=\mathrm{j}^{*} 0.1$

$X G \_$reaktor $=j * 0.25$;

XG1_1 = j*0.15;

XG1_2 $=\mathrm{j} * 0.15$

XG1_0 = j*0.15;

$\mathrm{XG} 2 \_1=\mathrm{j} * 0.15$

$\mathrm{XG2} 2 \mathrm{2}=\mathrm{j} * 0.15$

$\mathrm{XG} 2 \_0=\mathrm{j} * 0.05$

$\mathrm{XT} 1 \_1=\mathrm{j} * 0.10$

$\mathrm{XT} 1 \_2=\mathrm{j} * 0.10$

$\mathrm{XT} 1 \_0=\mathrm{j} * 0.10$

$\mathrm{XT} 2 \_1=\mathrm{j} * 0.10$

$\mathrm{XT} 2 \_2=\mathrm{j} * 0.10$

$\mathrm{XT} 2 \_0=\mathrm{j} * 0.10$

XL12_1 $=\mathrm{j} * 0.125$;

XL12_2 $=\mathrm{j}^{*} 0.125$

XL12_0 $=\mathrm{j}^{*} 0.30$;

XL13_1 $=\mathrm{j}^{*} 0.15$;

XL13_2 $=\mathrm{j} * 0.15$;

XL13_0 $=\mathrm{j} * 0.35$;

XL23_1 $=\mathrm{j} * 0.25$;

XL23_2 $=\mathrm{j} * 0.25$;

XL23_0 $=\mathrm{j} * 0.7125$;

$\%$ Impedansi transformasi Segitiga ke

Bintang ditinjau dari bus 3 untuk urutan positif dan negatif :

Z1s_pn =

$(\mathrm{XL12} 1 *$ XL13_1)/(XL12_1+XL13_1+XL2 3_1);

Z2s_pn =

$(\mathrm{XL12} 1 *$ XL23_1)/(XL12_1+XL13_1+XL2 3_1);

Z3s_pn =

$(\mathrm{XL13} 1 *$ XL23_1)/(XL12_1+XL13_1+XL2 3_1);

$\%$ Impedansi urutan positif dan negatif :

Zs1_pn = XG1_1+XT1_1+Z1s_pn;

$\mathrm{Zs} 2 \_$pn $=$XG2_1+XT2_1+Z2s_pn;
$\mathrm{Zpn}=$

((Zs1_pn*Zs2_pn)/(Zs1_pn+Zs2_pn))+Z3s_

pn;

Z33_1 = Zpn;

Z33_2 = Z33_1;

\% Impedansi transformasi Segitiga ke

Bintang ditinjau dari bus 3 untuk urutan nol :

Z1s_0 =

$\left(X L 12 \_0 * X L 13 \_0\right) /\left(X L 12 \_0+X L 13 \_0+X L 2\right.$ 3_0);

$\mathrm{Z} 2 \mathrm{~s} \_0=$

$\left(X L 12 \_0 * X L 23 \_0\right) /\left(X L 12 \_0+X L 13 \_0+X L 2\right.$

3_0);

$\mathrm{Z} 3 \mathrm{~s} \_0=$

$\left(X L 13 \_0 * X L 23 \_0\right) /\left(X L 12 \_0+X L 13 \_0+X L 2\right.$

3_0);

$\%$ Impedansi urutan nol :

Zs1_0 =

XG_reaktor+XG1_0+XT1_0+Z1s_0;

$\mathrm{Zs} 2 \_0=\mathrm{XT} 2 \_0+\mathrm{Z} 2 \mathrm{~s} \_0$;

Z33_0 =

$\left(\left(\mathrm{Zs} 1 \_0 * \mathrm{Zs} 2 \_0\right) /\left(\mathrm{Zs} 1 \_0+\mathrm{Zs} 2 \_0\right)\right)+\mathrm{Z} 3 \mathrm{~s} \_0$;

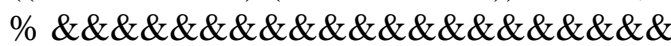

$\%$ \&\& Perhitungan arus gangguan $\& \&$

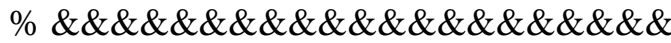

$\%$ Perhitungan arus gangguan tiga fasa

seimbang pada bus 3 :

I3_a_F = V3_a_0/(Z33_1+Zf);

$\mathrm{I} 3 \mathrm{~F}=\mathrm{abs}\left(\mathrm{I} 3 \_\mathrm{a} \_\mathrm{F}\right)$;

theta $=$

180/pi*atan2(imag(I3_a_F),real(I3_a_F));

$\operatorname{disp}('$

$\operatorname{disp}(|| \wedge \wedge \wedge \wedge \wedge \wedge \wedge \wedge \wedge \wedge \wedge \wedge \wedge \wedge \wedge \wedge \wedge \wedge \wedge \wedge \wedge \wedge \wedge \wedge \wedge \wedge \wedge \wedge \wedge \wedge \wedge \wedge \wedge \wedge \wedge$

$\wedge \wedge \wedge \wedge \wedge \wedge \wedge \mid ')$

disp('| Arus Gangguan Tiga Fasa Seimbang Pada Bus 3 |')

$\operatorname{disp}(' \mid------------1 ')$

disp('| I3_a : I3(F) sudut

')

$\operatorname{disp}(\mid) \quad(p u) \quad: \quad(p u) \quad($ derajat $)$

')

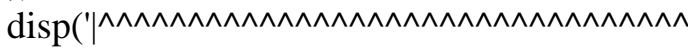

$\wedge \wedge \wedge \wedge \wedge \wedge \wedge \mid ')$

fprintf('|\%4.0f

:\%'n',I3_a_F),disp([I3F,theta])

$\%$ Perhitungan arus gangguan satu fasa ke tanah pada bus 3 :

I3 $0=$

V3_a_0/(Z33_1+Z33_2+Z33_0+3*Zf);

I3_1 = I3_0;

I3_2 = I3_0;

$\%$ Arus setiap fasa : 
$\mathrm{I}=\mathrm{A} *\left[\mathrm{I} 3 \_0 ; \mathrm{I} 3 \_0 ; \mathrm{I} 3 \_0\right]$;

$\mathrm{I} \_\mathrm{a}=\mathrm{I}(1)$;

$\mathrm{I} 3 \_\mathrm{b}=\mathrm{I}(2)$;

$\mathrm{I} 3 \_\mathrm{c}=\mathrm{I}(3)$;

$\mathrm{I} 3 \mathrm{~F}=\operatorname{abs}\left(\mathrm{I} 3 \_\mathrm{a}\right)$;

theta $=180 /$ pi*atan2(imag(I3_a),real(I3_a) $)$;

$\operatorname{disp}(\mid \wedge \wedge \wedge \wedge \wedge \wedge \wedge \wedge \wedge \wedge \wedge \wedge \wedge \wedge \wedge \wedge \wedge \wedge \wedge \wedge \wedge \wedge \wedge \wedge \wedge \wedge \wedge \wedge \wedge \wedge \wedge \wedge \wedge \wedge \wedge$

$\wedge \wedge \wedge \wedge \wedge \wedge \wedge \wedge \wedge \wedge$ ')

disp('| Arus Gangguan Satu Fasa ke Tanah pada Bus $3 \quad$ |')

disp('|-------------------'

$\begin{array}{lllllll}\operatorname{disp}(' \mid & \text { I3_a } & : & \text { I3_b } & : & \text { I3_c } & : \\ \text { I3(F) } & \text { sudut } & & \left.\mid{ }^{\prime}\right) & & & \\ \operatorname{disp}(|| & (p u) & : & (p u) & : & \text { (pu) } & :\end{array}$

(pu) (derajat) |')

$\operatorname{disp}(\mid \wedge \wedge \wedge \wedge \wedge \wedge \wedge \wedge \wedge \wedge \wedge \wedge \wedge \wedge \wedge \wedge \wedge \wedge \wedge \wedge \wedge \wedge \wedge \wedge \wedge \wedge \wedge \wedge \wedge \wedge \wedge \wedge \wedge \wedge \wedge$ $\wedge \wedge \wedge \wedge \wedge \wedge \wedge \wedge \wedge \wedge \wedge \mid ')$

fprintf('|'),disp([I3_a,I3_b,I3_c,I3F,theta])

$\%$ Perhitungan arus gangguan fasat ke fasa pada bus 3 :

I3_0 = 0;

I3_1 = V3_a_0/(Z33_1+Z33_2+Zf);

I3_2 = -I3_1;

$\%$ Arus setiap fasa :

$\mathrm{I}=\mathrm{A} *\left[13 \_0 ; \mathrm{I} 3 \_1 ; \mathrm{I} 3 \_2\right]$;

I3_a $=\mathrm{I}(1)$;

$\mathrm{I} 3 \_\mathrm{b}=\mathrm{I}(2)$;

I3_c = I (3);

$\mathrm{I} 3 \_\mathrm{F}=$

$1.732 *\left(V 3 \_a\right.$ _0 $) /\left(Z 33 \_1+Z 33 \_2+3 * Z f\right)$;

$\mathrm{I} 3 \mathrm{~F}=\operatorname{abs}\left(\mathrm{I} 3 \_\mathrm{F}\right)$;

theta $=180 /$ pi*atan2(imag $\left.\left(I 3 \_1\right), \operatorname{real}\left(I 3 \_1\right)\right)$; $\operatorname{disp}(\mid \wedge \wedge \wedge \wedge \wedge \wedge \wedge \wedge \wedge \wedge \wedge \wedge \wedge \wedge \wedge \wedge \wedge \wedge \wedge \wedge \wedge \wedge \wedge \wedge \wedge \wedge \wedge \wedge \wedge \wedge \wedge \wedge \wedge \wedge$

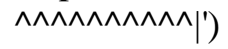

disp('| Arus Gangguan Fasa ke Fasa Pada

Bus 3

')

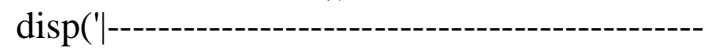

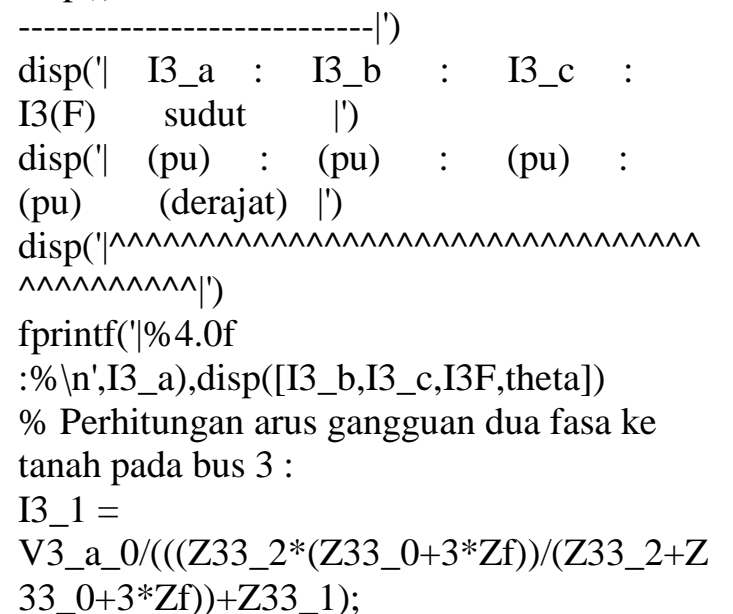

I3_2 = -(V3_a_0-Z33_1*I3_1)/Z33_2;

I3_0 = -(V3_a_0-

Z33_1*I3_1)/(Z33_0+3*Zf);

$\%$ Arus setiap fasa :

$\mathrm{I}=\mathrm{A} *\left[\mathrm{I} 3 \_0 ; \mathrm{I} 3 \_1 ; \mathrm{I} 3 \_2\right]$;

I3_a $=\operatorname{abs}(\mathrm{I}(1))$;

I3_b = abs(I(2));

$\mathrm{I} 3 \_\mathrm{c}=\operatorname{abs}(\mathrm{I}(3))$;

theta $1=180 / \mathrm{pi} * \operatorname{atan} 2(\operatorname{imag}(\mathrm{I}(1)), \operatorname{real}(\mathrm{I}(1)))$;

theta $2=180 / \mathrm{pi} * \operatorname{atan} 2(\operatorname{imag}(\mathrm{I}(2)), \operatorname{real}(\mathrm{I}(2)))$;

theta3 $=180 /$ pi*atan2 $(\operatorname{imag}(\mathrm{I}(3)), \operatorname{real}(\mathrm{I}(3)))$;

$\%$ Arus gangguan :

$\mathrm{I} 3 \_\mathrm{F}=\mathrm{I}(2)+\mathrm{I}(3)$;

$\mathrm{I} 3 \mathrm{~F}=$ abs(I3_F);

theta $=180 /$ pi*atan2 $($ imag(I3_F),real(I3_F)); $\operatorname{disp}(\mid \wedge \wedge \wedge \wedge \wedge \wedge \wedge \wedge \wedge \wedge \wedge \wedge \wedge \wedge \wedge \wedge \wedge \wedge \wedge \wedge \wedge \wedge \wedge \wedge \wedge \wedge \wedge \wedge \wedge \wedge \wedge \wedge \wedge \wedge$

$\wedge \wedge \wedge \wedge \wedge \wedge \wedge \wedge \wedge \wedge \wedge \wedge \wedge$ ')

disp('| Arus Gangguan Dua Fasa ke Tanah

Pada Bus 3

disp('|------------------------')

disp('| I3_a : I3_b sudut : I3_c sudut

: I3(F) sudut $\left.\left.\right|^{\prime}\right)$

$\operatorname{disp}(\mid)(\mathrm{pu}):(\mathrm{pu})($ derajat$):(\mathrm{pu})$

(derajat) : (pu) (derajat) |')

$\operatorname{disp}(\mid \wedge \wedge \wedge \wedge \wedge \wedge \wedge \wedge \wedge \wedge \wedge \wedge \wedge \wedge \wedge \wedge \wedge \wedge \wedge \wedge \wedge \wedge \wedge \wedge \wedge \wedge \wedge \wedge \wedge \wedge \wedge \wedge \wedge$

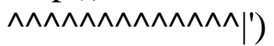

fprintf('|\%7.0f :\%8.3f \%8.3f :\%8.3f \%8.3f

:\%8.3f \%8.3f |

In',I3_a,I3_b,theta2,I3_c,theta3,I3F,theta)

$\operatorname{disp}(\mid \wedge \wedge \wedge \wedge \wedge \wedge \wedge \wedge \wedge \wedge \wedge \wedge \wedge \wedge \wedge \wedge \wedge \wedge \wedge \wedge \wedge \wedge \wedge \wedge \wedge \wedge \wedge \wedge \wedge \wedge \wedge \wedge \wedge \wedge \wedge \wedge \wedge$

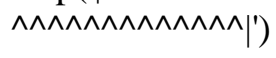

Hasil perhitungan arus gangguan hubung singkat sistem tenaga listrik, dengan menggunakan aplikasi Matlab terlihat pada tabel berikut :

$>>$

$\mid \wedge \wedge \wedge \wedge \wedge \wedge \wedge \wedge \wedge \wedge \wedge \wedge \wedge \wedge \wedge \wedge \wedge \wedge \wedge \wedge \wedge \wedge \wedge \wedge \wedge \wedge \wedge \wedge \wedge \wedge \wedge \wedge \wedge \wedge \wedge \wedge \wedge \wedge$ $\wedge \wedge \wedge \wedge \wedge \wedge \wedge \wedge \mid$

| Arus Gangguan Tiga Fasa Seimbang Pada Bus 3 |

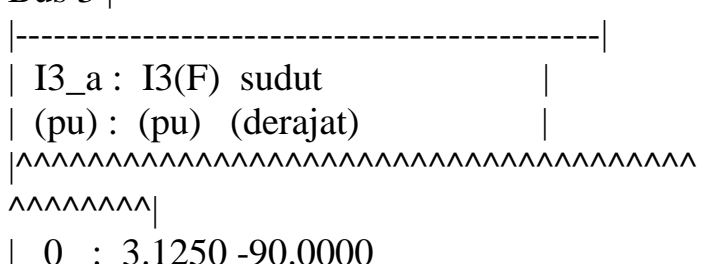

$\mid \wedge \wedge \wedge \wedge \wedge \wedge \wedge \wedge \wedge \wedge \wedge \wedge \wedge \wedge \wedge \wedge \wedge \wedge \wedge \wedge \wedge \wedge \wedge \wedge \wedge \wedge \wedge \wedge \wedge \wedge \wedge \wedge \wedge \wedge \wedge \wedge \wedge \wedge$ $\wedge \wedge \wedge \wedge \wedge \wedge \wedge \wedge \wedge \wedge \wedge \wedge \wedge \wedge \wedge$ 
| Arus Gangguan Satu Fasa ke Tanah pada Bus 3

I3_a : I3_b : I3_c : I3(F) sudut $(\mathrm{pu}):(\mathrm{pu}):(\mathrm{pu}):(\mathrm{pu})$ (derajat)

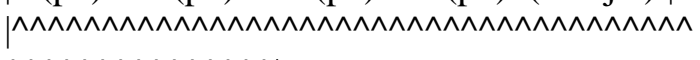

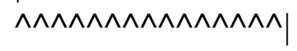

| 0-2.7253i $0-0.0000 \mathrm{i} \quad 0-0.0000 \mathrm{i} 2.7253$ 90.0000

$\mid \wedge \wedge \wedge \wedge \wedge \wedge \wedge \wedge \wedge \wedge \wedge \wedge \wedge \wedge \wedge \wedge \wedge \wedge \wedge \wedge \wedge \wedge \wedge \wedge \wedge \wedge \wedge \wedge \wedge \wedge \wedge \wedge \wedge \wedge \wedge \wedge \wedge \wedge$ $\wedge \wedge \wedge \wedge \wedge \wedge \wedge \wedge \wedge \wedge \wedge \wedge \wedge \wedge \wedge \wedge \wedge \wedge \wedge \wedge \wedge \wedge \wedge$

Arus Gangguan Fasa ke Fasa Pada Bus 3

(

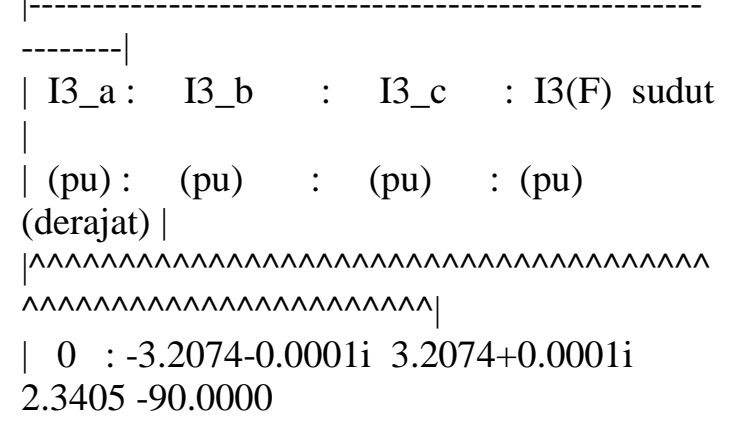

$\mid \wedge \wedge \wedge \wedge \wedge \wedge \wedge \wedge \wedge \wedge \wedge \wedge \wedge \wedge \wedge \wedge \wedge \wedge \wedge \wedge \wedge \wedge \wedge \wedge \wedge \wedge \wedge \wedge \wedge \wedge \wedge \wedge \wedge \wedge \wedge \wedge \wedge \wedge$ $\wedge \wedge \wedge \wedge \wedge \wedge \wedge \wedge \wedge \wedge \wedge \wedge \wedge \wedge \wedge \wedge \wedge \wedge \wedge \wedge \wedge \wedge \wedge \wedge \wedge \mid$

| Arus Gangguan Dua Fasa ke Tanah Pada Bus 3

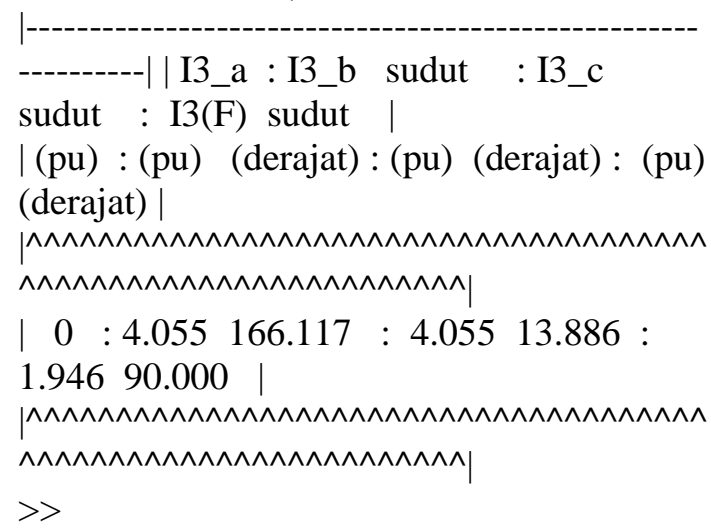

\section{HASIL DAN PEMBAHASAN}

Berdasarkan perhitungan arus hubung singkat yang dilakukan pada sistem tenaga listrik diatas, nilai arus ganguan yang paling besar terdapat pada gangguan hubung singkat 3 fasa dengan nilai arus gangguan sama besarnya pada setiap fasa, yaitu j3,125 pu atau $3,125 \angle-90^{\circ}$ pu.

Nilai arus gangguan hubung singkat baik yang dihitung secara manual maupun dengan Matlab menghasilkan harga yang sama.

\section{SIMPULAN}

1. Gangguan hubung singkat terhadap sistem tenaga listrik yang begitu rumit jaringannya dapat dianalisis secara mudah dengan menggunakan metode Thevenin dan nilainya dapat dibandingkan dengan aplikasi Matlab.

2 Besar tegangan dan impedansi ekivalen Thevenin ditentukan berdasarkan letak titik gangguan yaitu titik F-N. Jika gangguan pada bus-3 titik F-N adalah antara bus-3 dengan netral, begitu juga bila gangguannya pada bus yang lain.

3 Besarnya nilai arus gangguan hubung singkat tiga fasa dibandingkan dengan jenis gangguan hubung singkat lainnya karena dipengaruhi oleh impedansi urutan positif.

\section{UCAPAN TERIMA KASIH}

Terima kasih disampaikan kepada Redaksi Jurnal Menara Ilmu UMSB yang telah memberikan kesempatan kepada penulis untuk dapat menerbitkan tulisan di Jurnal Menara Ilmu UMSB edisi kali ini, serta berbagai pihak yang telah memberi dorongan dan semangatnya semoga Allah akan membalasinya menjadi amal shaleh. Segala saran dan masukan dari pembaca akan menjadi lebih sempurna pada tulisan ini, wassalam.

\section{DAFTAR PUSTAKA}

Afrianita, Reri., "Aplikasi Matlab untuk Matematika Rekayasa”, FT Unand Padang, 2011.

C. Dunken Glover, Mulukutla S. Sarma, Thomas J. Overbye, "Power System Analysis and Design", Fift Edition, Cengage Learning, Stamford Place, 2012.

Edminister, Joseph A., "Theory and Problem of Electric Circuit", Mc GrawHill, 1972

Gonen, Turan., "Modern Power System Analysis", John Wiley \& Sons Inc, USA, 1988.

Grainger, John J., Stevenson, William D., Jr., "Power System Analysis", McGrawHill, Inc, 1994.

Mohamed E. El-Hawary, "Electrical Power System, Design and Analysis", IEEE Inc., 1992.

Masykur, SJ. "Analisa Gangguan Hubung Singkat Tiga Fasa pada Sistem Tenaga 
Listrik Dengan Metode Thevenin”, Jurnal Sistem Teknik Industri Vol. 6, No. 3, Juli 2005.

Saadat Hadi, "Power System Analysis", $3^{\text {rd }}$ Edition, McGraw-Hill, 2011.

Sahid, Drs., M.Sc., "Panduan Praktis Matlab", Penerbit Andi Yogyakarta, Juni 2006.

Savas Koc, Zfer Aygogmus. “A Matlab/GUI Based Fault Simulation Tool for Power System Education", Mathematical and Computational Application, Vol.14, No.3, pp. 207-217, 2009 Association for Scientific Research.

Stephen Marx., Dean Bender. "An Introduction to Symmetrical Component, System Modeling and Fault Calculation", Washington State University Pullman, Washington.

S.S. Vadhera., "Power System Analysis \& Stability", Khanna Publisher, Delhi, March 1981.

Stag, G.W., El-Abiad, A.H., "Computer Methods in Power System Analysis”, Mc Graw-Hill, 1968 